\title{
Psychosocial impact of parenting children with intellectual disabilities in Bangladesh
}

\author{
Mohammad Aminul Islam ${ }^{1}$, Md. Azibar Rahman ${ }^{2}$, Sharmin Akhtar ${ }^{3}$ \\ ${ }^{1}$ Department of Media Studies and Journalism, University of Liberal Arts Bangladesh (ULAB), Dhaka, Bangladesh \\ ${ }^{2}$ Department of Psychology, Shalua Degree College, Rajshahi, Bangladesh \\ ${ }^{3}$ Faculty of Business, Economics and Social Development, University Malaysia Terengganu, Terengganu, Malaysia
}

\begin{abstract}
Article Info
Article history:

Received Jun 16, 2021

Revised Nov 6, 2021

Accepted Nov 21, 2021

Keywords:

Children

Depression

Intellectual disabilities

Marital satisfaction

Mental health

Parents

ABSTRACT

It is well documented that raising a child with an intellectual disability negatively affects the mental health and marital relationships of the parents as they encounter additional social, psychological, financial, and physical burdens. But little is known about the phenomena from the context of Bangladesh. This study aimed to investigate the effect of having a child with an intellectual disability on marital satisfaction and the mental wellbeing of the parents. It assessed the depression and marital satisfaction of randomly selected 60 parents (both father and mother) having a child with an intellectual disability and compared with the same number of parents without a child of intellectual disability. It used an improvised Bangla version of the beck depression inventory (BDI-II) and a relationship assessment scale (RAS) to measure the severity of depression and the level of marital satisfaction among the participants. Most of the parents of children with intellectual disabilities suffer from moderate depression. Meanwhile, most of the parents of children without intellectual disabilities suffer from mild mood disturbance. Parents of children with intellectual disabilities suffer from a higher level of depression and have a higher level of marital satisfaction compared to the parents of children without intellectual disabilities in Bangladesh.
\end{abstract}

This is an open access article under the CC BY-SA license.

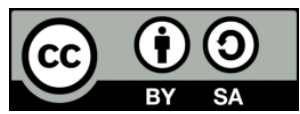

\section{Corresponding Author:}

Sharmin Akhtar

Faculty of Business, Economics and Social Development, University Malaysia Terengganu

Kuala Nerus 21030, Terengganu, Malaysia

Email: sharmin.pop.sc.ru@gmail.com

\section{INTRODUCTION}

Mental health and marital satisfaction are growing concerns in modern society. Moreover, there is an increasing trend in the prevalence of children with intellectual disabilities around the world. Over the past few decades, the issues of parenting children with intellectual disabilities and their psycho-social impact on the parents are getting much attention to scholars from multiple disciplines, and get spaces in public health debates and discussions around the world. Parents of children often experience more social, psychological, physical, and financial burdens compared to parents of children without intellectual disabilities [1], [2]. The general factors for the burden are stigma, lack of informal and formal support systems to cope with the challenges of raising children [3] in developing countries like Bangladesh. Such experiences often negatively affect their mental health and psychological well-being and family life [4]. Several studies show that taking care of children causes different forms and levels of depression, anxiety, and a high level of stress, distress, worries, grief, and bitterness [5]. 
The convention on the rights of persons with disabilities defines disability as "persons with disabilities include those who have long-term physical, mental, intellectual or sensory impairments which in interaction with various barriers may hinder their full and effective participation in society on an equal basis with others" [6]. Globally more than a billion people, live with some form of disability. The prevalence of people with an intellectual disability is almost double in developing countries compared to high-income countries [7]. An individual with intellectual disabilities encounters problem to understand new or complex information and apply new skills in their daily lives [8]. But there is a dearth of reliable data on children with disabilities in Bangladesh [9]. The number of people with disabilities ranged from $1.4 \%$ to $9 \%$ of the population. Meanwhile, the number of children with disabilities in the country ranged between $1.4 \%$ and $17.5 \%[10]$.

Depression is a common mental illness that affects a person's psychosocial life and well-being in a variety of ways, including persistent feelings of sadness, emptiness, or hopelessness, angry outbursts, frustration, loss of interest or pleasure in normal activities, sleep disturbances, tiredness, lack of energy, feelings of worthlessness, thoughts of death or suicide, and social-relational disfunctions [11]-[13]. On the other hand, marital satisfaction is a multifaceted concept, which encompasses individual, interpersonal, social, psychological, cultural, and physiological dimensions of a married couple [14], [15] in their life. In a general sense, marital satisfaction is an individual's attitude toward his or her marital relationship [16]. It indicates, a sense of happiness, satisfaction, and joy [17], a state of contentment, satisfaction, and pleasure [18], and fulfillment of expectations from each other when a married couple takes into consideration all aspects of their marriage. It is well documented that parenting children with intellectual disabilities negatively affect the quality of life [19]-[21], satisfaction with life and marital relations [21]-[23], and mental health. Several studies indicate that the parents suffer from a higher level of depression, anxiety, and stress compared to parents of children without intellectual disability [5], [24], [25]. Meanwhile, Uskun and Gundogar [5] found that the levels of stress, depression, and anxiety among parents of children with a disability were higher in Turkey. A similar study in Pakistan found that the rates of anxiety and depression were higher among mothers compared to fathers [26]. Another study found that the parents who have better marital quality encounter lower parenting stress and fewer depressive symptoms irrespective of their socioeconomic status, child characteristics, and social support [27]. Meanwhile, Tov and Kaniel [28] argued that the quality of marriage enhances the ability to cope with the stress of parenting children with intellectual disabilities. Several studies found that there is a significant relationship between marital satisfaction, parenting stress, and child behavioral problems [29], [30].

From various studies, it is evident that the effect of caring for a child with intellectual disability yields mixed results. Some of the studies indicate that there is no significant difference in marital satisfaction of mothers of children with intellectual disability and those mothers having no child with intellectual disability [23], [29], [31]. Most of the earlier studies explored the dynamics of parenting children with intellectual disabilities and its impact on the quality of life and wellbeing among the parents in western and developed countries. The studies tried to investigate the impact of raising a child with an intellectual disability separately on father and mother. They did not consider both father and mother together as a unit of analysis. Besides, the context of Bangladesh is different in terms of social, cultural, and religious dynamics of parenting and the relationship between a husband and a wife. There are three types of families in Bangladeshjoint, extended, and nuclear [32]. It is essential to keep up a formal relationship with the other family members to sustain the stability of family structure in raising a child. Thus, the members of the family take part to build up a good relationship with neighbors, and other relatives function as social capital for the parents [33]. In Bangladesh, parents are not a separate entity; rather they are part of the whole family. In most cases, the decision to take the baby and their rearing are influenced by other members of the family. Because social and family bonding is regarded most precious in the country [34]. However, very little is known about the psychological and relational dimensions of parenting a child with an intellectual disability from the context of a developing country like Bangladesh. This study aimed to fill this knowledge gap. Therefore, it investigated the effect of having a child with an intellectual disability on marital satisfaction and the mental wellbeing of the parents. More precisely, this study explored the prevalence of depression and the level of marital satisfaction among parents of children with intellectual disabilities and parents of children without intellectual disabilities. It also explored the factors associated with marital satisfaction and depression among the parent groups in Bangladesh.

\section{RESEARCH METHOD}

This cross-sectional study was conducted in the Rajshahi City Corporation area, a northern city that is about 300 kilometers northwest of Dhaka, the capital city of Bangladesh. Informed oral consent was taken from the participants. The purpose and procedures, expected duration of filing out the questionnaire, right to 
decline or withdraw at any stage of the research, potential risk, discomfort, or adverse effects of taking part, and whom to and how to contact for any questions regarding the study were explained to the participants in clear and simple language in Bangla.

\subsection{Participants}

Data were collected from a total of 120 parents of children with intellectual disability and without intellectual disability. The participants of the study comprised 60 parents (both fathers and mothers) having at least one child with an intellectual disability and another 60 parents of children without an intellectual disability.

\subsection{Procedure}

A non-probability snowball sampling technique was used to reach the parents. At first, data were collected from the parents (both mother and father) of children with intellectual disabilities. Later, a similar number of parents of children without an intellectual disability were reached by following the same process in the study area. Initially, data were collected from the parents with whom the first and second author of this study had personal acquaintances. The prospective participants were contacted through mobile phone calls. Upon their preliminary consent to take part in the study, the first and second author of this study met them at their houses. The researchers did not perform any clinical procedure on the children to identify if they were intellectually disabled. Rather, it was the parents who informed whether their children were suffering from an intellectual disability or with normal intelligence. Later, informed oral consent was taken by explaining the research's objectives, risks, and benefits of taking part in it in face-to-face situations.

\subsection{Data collection}

Primary data for the study were collected using a duly pretested semi-structured questionnaire that contained questions about demographic features, child's features, depression, and marital satisfaction, age, gender, number of children, employment status, socioeconomic status, and education level. Meanwhile, psychometric tools such as Bangla versions of the beck depression inventory (BDI-II) [35], [36] and relationship assessment scale (RAS) [37], were used to measure the severity of depression and level of marital satisfaction.

\subsection{Beck depression inventory (BDI-II)}

The BDI-II is a 21-question multiple-choice self-report psychometric tool widely used for measuring the severity of depression. Beck et al. [35] originally developed it. Meanwhile, Alim et al., [36] validated it in Bangla. Each question of the tool contains a set of at least four responses ranging from 0 (symptom absent) to 3 (severe symptoms). The first question was as: $0=\mathrm{I}$ do not feel sad, $1=\mathrm{I}$ feel sad, $2=\mathrm{I}$ am sad all the time and I can't snap out of it, and 3=I am so sad or unhappy that I can't stand it. In the scale, the minimum score is 0 and the maximum score is 63 . Higher scores indicate greater symptom severity. A score of 1-10 indicates normal or no depression, but there are ups and downs in their emotions. Those who score 11-16 indicate mild mood disturbance, 17-20 indicate borderline clinical depression, 21-30 indicate moderate depression, 31-40 indicate severe depression and over 40 indicate extreme depression.

\subsection{Relationship assessment scale (RAS)}

The level of marital satisfaction among the participants was measured using an improvised Bangla version of the RAS. It is a 7-item scale originally developed by Hendrick [38]. The first question of scale was 'How well does your partner meet your needs?' Participants were asked to answer each item using a 5-point scale ranging from 1 (low satisfaction) to 5 (high satisfaction). Items 4 and 7 are reverse-scored. The higher the score, the more satisfied the respondent is with his/her relationship.

\subsection{Data analysis}

Statistical package for social science (SPSS) version-23 was used to analyze the relationship between mental health (depression) and marital satisfaction. The analysis comprises variables measuring the severity of depression and the level of marital satisfaction. Various descriptive statistics such as frequencies, percentages, means, and standard deviations were used to present the data. Statistical tests such as $\chi^{2}$-test and linear regression were performed to determine the association among the variables.

\section{RESULTS}

\subsection{Demographic features}

The average age of parents of children without an intellectual disability was 34.21 years (Min=21, $\mathrm{Max}=54, \mathrm{SD}=7.844$ ). Meanwhile, parents of children with intellectual disabilities were on average 41.35 
years old $(\mathrm{Min}=25$ years, $\mathrm{Max}=62$ years, $\mathrm{SD}=8.217)$. Table 1 represent that $38(63.3 \%)$ of participants among parents of children without an intellectual disability were aged between 18-35 years, meaning that most of them were young adults. Most of the participants among parents of children with intellectual disabilities were middle-aged adults (36-55 years). Parents of children without intellectual disability earned on an average 27,733.33 Taka (Bangladeshi currency [hereafter 'Tk'], 1 USD=84 Taka) per month (Min=0, Max=90,000, $\mathrm{SD}=24,717.2942$ ). The average income of parents of children with intellectual disabilities was Tk 26,516.67 per month ( $\mathrm{Min}=0, \mathrm{Max}=80,000, \mathrm{SD}=22,342.095)$. Most of the participants from both groups were from the low-income group who earned a maximum of $\mathrm{Tk} 30,000$ a month. Furthermore, most of the parents of children without intellectual disability had high school/secondary level education 26 (43.3\%). On the contrary, $39(65 \%)$ parents of children with intellectual disabilities had a university degree or above. In most cases, participants from both groups had two children as shown in Table 1.

Table 1. Demographic features of both respondents' groups

\begin{tabular}{|c|c|c|c|}
\hline Participants & Indicators & $\begin{array}{l}\text { Parents of children without } \\
\text { intellectual disability } \\
\mathrm{n}(\%)\end{array}$ & $\begin{array}{c}\text { Parents of children with } \\
\text { intellectual disability } \\
\mathrm{n}(\%)\end{array}$ \\
\hline \multirow[t]{3}{*}{ Age group (years) } & Young adults (18-35) & $38(63.3)$ & $12(20)$ \\
\hline & Middle aged adults (36-55) & $22(36.7)$ & $45(75)$ \\
\hline & Older adults (56 and above) & $0(0)$ & $3(5)$ \\
\hline \multirow[t]{3}{*}{ Education } & Primary level & $6(10.0)$ & $9(15)$ \\
\hline & Secondary level & $26(43.3)$ & $12(20)$ \\
\hline & University degree or above & $28(46.7)$ & $39(65)$ \\
\hline \multirow{3}{*}{$\begin{array}{l}\text { The income per } \\
\text { month }\end{array}$} & Low income (Tk 0-Tk 30,000) & $33(55.0)$ & $31(51.7)$ \\
\hline & Middle income (Tk 31,000- Tk 60,000) & $22(36.7)$ & $24(40.0)$ \\
\hline & High income (Tk 61,000-Tk 90,000) & $5(8.3)$ & $5(8.3)$ \\
\hline \multirow[t]{3}{*}{ Number of children } & 1 & $21(35.0)$ & $15(25.0)$ \\
\hline & 2 & $27(45.0)$ & $31(51.7)$ \\
\hline & 3 & $12(20.0)$ & $14(23.3)$ \\
\hline
\end{tabular}

\subsection{Features of children with intellectual disability}

Most of the parents of children with intellectual disabilities (83.3\%) reported that their children were mainly suffering from low intellectual development. Meanwhile, $16.7 \%$ of parents reported that their children were suffering from speech disabilities. About half of the children (40.0\%) were aged between 11-15 years. The details are shown in Table 2.

Table 2. Features of children with intellectual disability

\begin{tabular}{cccc}
\hline \multicolumn{2}{c}{ Category } & Frequency (n) & Percent (\%) \\
\hline Types of disability & Cognitive delays & 50 & 83.3 \\
& Speech disability & 10 & 16.7 \\
Age of the children & $0-5$ & 8 & 13.3 \\
& $6-10$ & 10 & 16.7 \\
& $11-15$ & 24 & 40.0 \\
& $16-20$ & 6 & 10.0 \\
& $21-25$ & 10 & 16.7 \\
& $26-$ above & 2 & 3.3 \\
\hline
\end{tabular}

\subsection{Presence of depression and marital satisfaction}

The mean score in the BDI-II for parents of children without an intellectual disability is 13.70, which indicates that most of them have mild mood disturbance. But the score for the parents of children with an intellectual disability is 27.26 , meaning that most of them suffer from moderate depression. Table 3 shows that the mean score in RAS for the parents of children without an intellectual disability is 25.83. The score for the parents of children with an intellectual disability is 26.68 . The scores indicate that participants from both groups are almost similarly satisfied with their marital life.

Table 3. Presence of marital satisfaction and depression among parents of children without intellectual disability and parents of children with intellectual disability

\begin{tabular}{cccccc}
\hline Items & Levels & Minimum & Maximum & Mean & Std. deviation \\
\hline Parents of children without intellectual disability & Marital satisfaction & 15.0 & 32.0 & 25.83 & 4.3264 \\
& Depression & 7.00 & 19.00 & 13.70 & 2.58614 \\
& Marital satisfaction & 19.00 & 32.00 & 26.68 & 3.21802 \\
Parents of children with intellectual disability & Depression & 17.00 & 36.00 & 27.26 & 3.46834 \\
\hline
\end{tabular}

Int J Public Health Sci, Vol. 11, No. 1, March 2022: 211-219 


\subsection{Levels of depression and marital satisfaction}

Table 4 presents that the parents of children with intellectual disabilities are mainly suffer from borderline clinical depression to severe depression. On the other hand, mild mood disturbance is the most common among parents of children without intellectual disabilities. Among the parents of children without intellectual disability, $46(76.7 \%)$ had mild mood disturbance and $8(13.3 \%)$ participants of the group suffer from borderline depression. On the other hand, 49 (81.7\%) parents of children with intellectual disabilities suffer from moderate depression and $8(13.3 \%)$ of the parents suffer from severe depression. In addition, 42 $(70 \%)$ parents of children without intellectual disability informed that they were highly satisfied with their marital relations. On the other hand, $50(83.3 \%)$ parents of children with intellectual disabilities reported that the level of their marital satisfaction was high. This indicates caring for children with an intellectual disability did not affect their marital relationships.

Table 4. Level of depression and marital satisfaction among parents of children without intellectual disability and parents of children with intellectual disability

\begin{tabular}{cccc}
\hline \multirow{2}{*}{ Items } & Levels & $\begin{array}{c}\text { Parents of children without } \\
\text { intellectual disability } \\
\text { n }(\%)\end{array}$ & $\begin{array}{c}\text { Parents of children with intellectual } \\
\text { disability } \\
\text { n }(\%)\end{array}$ \\
\hline Depression & Normal (Not depressed) & $6(10.0)$ & $0(0.0)$ \\
& Mild mood disturbance & $46(76.7)$ & $0(0.0)$ \\
& Borderline clinical depression & $8(13.3)$ & $3(5.0)$ \\
& Moderate depression & $0(0.0)$ & $49(81.7)$ \\
& Severe depression & $0(0.0)$ & $8(13.3)$ \\
Marital & Extreme depression & $0(0.0)$ & $0.0)$ \\
satisfaction & Low & $0(0.0)$ & $0.0)$ \\
& Average & $18(30.0)$ & $10(16.7)$ \\
\hline
\end{tabular}

\subsection{Association between depression, marital satisfaction, and demographic variables}

Table 5 represents that there is a negative relationship between depression and marital satisfaction $\left(\chi^{2}=-.030, \mathrm{p}=.819\right)$ among the parents of children without intellectual disability. Meanwhile, the level of depression among the parents is significantly associated with income $(\chi 2=-.280, p=.030)$, education $(\chi 2=-.354, \mathrm{p}=.005)$ and gender $\left(\chi^{2}=.277, \mathrm{p}=.032\right)$.

Table 5. Association between depression, marital satisfaction, and demographic variables of parents of children without intellectual disability

\begin{tabular}{cccccccc}
\hline Items & Gender & Age & Children number & Education & Income & Intellectually disable child's age & Depression \\
\hline $\begin{array}{c}\text { Depression } \\
\begin{array}{c}\text { Marital } \\
\text { Satisfaction }\end{array}\end{array}$ & $.277^{*}$ & -.224 & -.081 & $-.354^{* *}$ & $-.280^{*}$ & -.140 & 1 \\
\hline$* *$ significant at the 0.01 & -.047 & .065 & .033 & .048 & .070 & -.030 \\
\hline
\end{tabular}

**significant at the 0.01 level (2-tailed), *significant at the 0.05 level (2-tailed)

Meanwhile, Table 6 shows that there is a negative correlation between depression and marital satisfaction $(\chi 2=-.018, \mathrm{p}=.891)$. However, there is a significant positive association between depression and the age of the intellectually disabled child $(\chi 2=.331, \mathrm{p}=.010)$. On the other hand, marital satisfaction is significantly associated with age $(\chi 2=.313, \mathrm{p}=.015)$ and family income $(\chi 2=.301, \mathrm{p}=.019)$.

Table 6. Association between depression, marital satisfaction, and demographic variables of parents of children with intellectual disability

\begin{tabular}{cccccccc}
\hline Items & Gender & Age & Children number & Education & Income & Intellectually disable child's age & Depression \\
\hline $\begin{array}{c}\text { Depression } \\
\text { Marital }\end{array}$ & .058 & .059 & .086 & -.131 & -.090 & $.331 * *$ & 1 \\
$\begin{array}{c}\text { Satisfaction } \\
\text { S* Correlation is significant at the } 0.01 \text { level (2-tailed) }\end{array}$ & -.235 & $.313 *$ & -.017 & .109 & $.301 *$ & .212 & -.018 \\
\hline
\end{tabular}

**Correlation is significant at the 0.01 level (2-tailed), *significant at the 0.05 level (2-tailed)

\subsection{Factors associated with the level of marital satisfaction among parents of children with intellectual disability}

The level of marital satisfaction is influenced by the following factors: satisfaction with overall all relationships with a partner and the family members, having a love for a partner, the number of problems in 
the relationship, the number of relatives with regular contact, frequency of seeing or hearing relatives, the number of relatives available for seeking help, availability of relatives for making any important decision, availability of friends for making decision, and age of the intellectually challenged child as shown in Table 7.

Table 7. Regression of different factors in marital satisfaction of parents of children with intellectual

\begin{tabular}{|c|c|c|c|c|}
\hline Variable & $B$ & $S E$ & $t$ & $p$ \\
\hline Intercept & .040 & .454 & .089 & .930 \\
\hline Demands met by the partner & -.225 & .072 & -3.128 & .004 \\
\hline Satisfaction with overall relationship & .281 & .057 & 4.959 & .000 \\
\hline Love for partner & .444 & .048 & 9.241 & .000 \\
\hline Number of problems in the relationship & -.482 & .123 & -3.924 & .000 \\
\hline Number of relatives with regular contact & .218 & .051 & 4.269 & .000 \\
\hline Frequency of seeing or hearing relatives & -.126 & .045 & -2.795 & .009 \\
\hline Number of relatives for seeking help & .454 & .117 & 3.897 & .000 \\
\hline Availability of relatives for making the decision & -.401 & .121 & -3.304 & .002 \\
\hline Availability of friends for making the decision & .190 & .084 & 2.264 & .031 \\
\hline Age of intellectually challenged child & .075 & .041 & 1.823 & .074 \\
\hline
\end{tabular}

\subsection{Factors associated with the level of depression among parents of children with intellectual disability}

Multiple factors contribute to the prevalence of depression among parents with intellectual disabilities. The factors include demands met by the partner, love for the partner, frequency of seeing or hearing from relatives, the number of relatives and friends to talk private matters, frequency of seeing close friends, a sense that there is someone to consult with any issue or problem, a sense that there is someone who cares for the well-being, and a feeling that there is someone who may help in need as shown in Table 8.

Table 8. Regression of different factors in depression among parents of children with intellectual disability

\begin{tabular}{lcccc}
\hline \multicolumn{1}{c}{ Variable } & $B$ & $S E$ & $t$ & $p$ \\
\hline Intercept & 6.790 & 2.668 & 2.545 & .018 \\
Demands met by the partner & .912 & .430 & 2.119 & .045 \\
Love for partner & .283 & .150 & 1.884 & .072 \\
Frequency of seeing or hearing from relatives & .601 & .223 & 2.697 & .013 \\
Number of relatives to talk private matters & -.795 & .304 & -2.616 & .015 \\
Number of friends talk about private matters & .580 & .241 & 2.408 & .024 \\
Frequency of seeing close friends & -.808 & .276 & -2.931 & .007 \\
Feel that there is someone to consult with & .671 & .352 & 1.905 & .069 \\
Feel that there is someone who cares for my well-being & .449 & .228 & 1.970 & .060 \\
Feel that there is someone who may help in need & .418 & .211 & 1.986 & .059 \\
\hline
\end{tabular}

\section{DISCUSSION}

The results of the study reveal that parents of children with intellectual disabilities suffer from a relatively higher level of depression compared to the parents of children without intellectual disabilities. This finding from Bangladesh is consistent with the results of many previous studies [39]. The challenges of taking care of children with intellectual disabilities impose several extra burdens on the parents such as the economic, emotional, social, cultural, and high prevalence of stigma about having a child with a disability. In a systematic review and meta-analysis, Yamaoka et al. [25], found that there is a significant association between raising a child with a disability and maternal psychological distress.

The positive association between gender and depression shows that fathers of children with intellectual disabilities suffer more from depression compared to mothers. However, the difference was not statistically significant. Earlier evidence shows that mothers of children with a disability experience more psychological distress compared to fathers of children without disabilities [25]. Another study found that mothers of children with intellectual disabilities have a high level of anxiety and depression [40]. Interestingly, findings of our study show that parents of children with intellectual disabilities had a higher score in of marital satisfaction than the parents of children without intellectual disabilities, which is similar to the findings of the several previous studies [22], [23], [41]. However, our finding contradicts the findings of other studies [21], [29]. Raising a child with an intellectual disability may bring the parents closer because of their common path of the journey through stress, anxiety, stigma, and prejudice. This stress may make their conjugal life less demanding and promote a helping attitude toward each other. Marital satisfaction depends 
on various individual, familial, and social factors. The financial condition of the parent may have a significant influence on marital satisfaction. Another study found closeness in the mother-child relationship and household income has a significant effect on the level of marital satisfaction [42]. However, in a recent study, Leung and Li-Tsang [43] found a higher parenting alliance was significantly associated with marital satisfaction.

Our findings show that mothers have lower marital satisfaction compared to that of fathers among the respondent group of parents of children with intellectual disabilities. The level of their marital satisfaction increased with the increase of their ages. We observed a positive relationship between depression and the number of children. This may be because parents need to provide care for each of them and arrange financial support for their educational and other support. However, we observed a negative relationship between the number of children and marital satisfaction. The finding is consistent with the earlier finding of $\mathrm{T}$ wenge et al. [15]. Besides, a negative relationship existed between the level of depression and the income of the parents.

The results of the study show that various factors contribute to the prevalence of depression and levels of marital satisfaction among the parents of children with intellectual disabilities. For example, the age of the intellectually challenged child and frequency of interactions with friends and relatives play a crucial role in mental health among the parents. The parents who feel that there is someone to consult with any issue or problem, and may help in need are more capable of coping with depression. The quality of relationships with family members of husband or wife, the number of relatives with regular contacts, frequency of seeing or hearing the relatives, the number of relatives available for seeking help, availability of relatives for making any important decision, and availability of friends for making decisions significantly affects their marital satisfaction.

The findings of the study put contribution to the understating of mental health problems and marital satisfaction of parents of children with intellectual disabilities and parents of children without intellectual disabilities from the perspective in Bangladesh. The results have both practical and theoretical implications. For example, policymakers, government, and non-government organizations may find it useful to ensure a better support system to cope with the adverse experiences due to raising children with intellectual disabilities. Researchers may find the results as a window to dig into deeper the issue from the context of a developing country.

Though the study has generated some insightful findings, the authors acknowledge a few limitations. This was a cross-sectional study that looks at the mental health and marital of parents of children with intellectual disabilities. It was a self-reported assessment and the perception of marital satisfaction and its expression may be influenced by the social-cultural and family influences. The study was conducted in a small geographic area with a small sample size that limits its acceptance as a complete representative sample for the entire country. However, the results of the study would be in the interest of policymakers, nongovernment organizations, and researchers in mental health, parenting, and intellectual disability. The researchers recommend that future researches investigate the phenomena among a larger sample to generate clearer insight about it from the context of the country [44]. An exploration of social support and the influence of social relationships of the parents of children with intellectual disability in coping with parental stress and mental health could help to understand the issue more deeply.

\section{CONCLUSION}

Parents of children with intellectual disabilities suffer from a higher level of depression and have a higher level of marital satisfaction compared to the parents of children without intellectual disabilities in Bangladesh. However, parenting a child with intellectual disabilities does not affect their marital satisfaction in the country's context. Multiple factors contribute to the prevalence of depression and levels of marital satisfaction among the parents. The factors include the age of the intellectually challenged child and the quality of relationships and frequency of interactions with friends and relatives. The availability of friends and relatives for making any important decisions and seeking help also play an important role in the cases. So, it is convincingly clear that interventions in the proper functioning of social and community life, and increased support from friends and relatives would help to cope with parental stress and depression among parents of children with intellectual disabilities. It would also enhance their quality of marital relationships and marital satisfaction.

\section{REFERENCES}

[1] A. Al-Krenawi, J. R. Graham, and F. Al Gharaibeh, "The impact of intellectual disability, caregiver burden, family functioning, marital quality, and sense of coherence," Disability \& Society, vol. 26, no. 2, pp. 139-150, Mar. 2011, doi: $10.1080 / 09687599.2011 .543861$. 
[2] F. D. Turan Gurhopur, "Family burden among parents of children with intellectual disability," Journal of Psychiatric Nursing, vol. 8, no. 1, pp. 9-16, 2017, doi: 10.14744/phd.2017.87609.

[3] B. Tigere and J. C. Makhubele, "The experiences of parents of children living with disabilities at Lehlaba protective workshop in Sekhukhune district of Limpopo province," African Journal of Disability, vol. 8, no. 0, pp. 1-9, Sep. 2019, doi: 10.4102/ajod.v8i0.528.

[4] R. K. Verma and M. T. Kishore, "Needs of Indian parents having children with intellectual disability," International Journal of Rehabilitation Research, vol. 32, no. 1, pp. 71-76, Mar. 2009, doi: 10.1097/MRR.0b013e32830d36b6.

[5] E. Uskun and D. Gundogar, "The levels of stress, depression and anxiety of parents of disabled children in Turkey," Disability and Rehabilitation, vol. 32, no. 23, pp. 1917-1927, Jan. 2010, doi: 10.3109/09638281003763804.

[6] F. Seatzu, "The convention on the rights of persons with disabilities and international human rights law," International Human Rights Law Review, vol. 7, no. 1, pp. 82-102, Jun. 2018, doi: 10.1163/22131035-00701004.

[7] P. K. Maulik, M. N. Mascarenhas, C. D. Mathers, T. Dua, and S. Saxena, "Prevalence of intellectual disability: A meta-analysis of population-based studies," Research in Developmental Disabilities, vol. 32, no. 2, pp. 419-436, Mar. 2011, doi: 10.1016/j.ridd.2010.12.018.

[8] M. Pipan, "Intellectual disability," Journal of Developmental \& Behavioral Pediatrics, vol. 33, no. 5, p. 386, Jun. 2012, doi: 10.1097/DBP.0b013e31825e2492.

[9] M. A. Islam, "An investigation into social support networks of parents of children with intellectual disability in Bangladesh," Mediterranean Journal of Clinical Psychology, vol. 8, no. 2, pp. 1-22, 2020, doi: 10.6092/2282-1619/mjcp-2506.

[10] UNICEF, "Situation analysis on children with disabilities in Bangladesh." pp. 1-7, 2014, Accessed: Aug. 16, 2021. [Online]. Available: www.unicef.org.bd.

[11] Mayo Clinic, "Depression (major depressive disorder)," Mayo Foundation for Medical Education and Research. 2018, Accessed: Aug. 16, 2021. [Online]. Available: https://www.mayoclinic.org/diseases-conditions/depression/symptoms-causes/syc-20356007.

[12] WHO, "Depression." 2021, Accessed: Aug. 16, 2021. [Online]. Available: https:/www.who.int/news-room/factsheets/detail/depression.

[13] F. Torres, "What Is Depression?," American Psychiatric Association. 2020, Accessed: Aug. 16, 2021. [Online]. Available: https://www.psychiatry.org/patients-families/depression/what-is-depression.

[14] M. Amiri, A. Khosravi, R. Chaman, H. Vahedi, and Z. Sadeqi, "Sexual satisfaction and influencing factors in women with fertility problems," Sexuality and Disability, vol. 34, no. 3, pp. 341-348, Sep. 2016, doi: 10.1007/s11195-016-9443-y.

[15] J. M. Twenge, W. K. Campbell, and C. A. Foster, "Parenthood and marital satisfaction: A meta-analytic review," Journal of Marriage and Family, vol. 65, no. 3, pp. 574-583, Aug. 2003, doi: 10.1111/j.1741-3737.2003.00574.x.

[16] M. E. King, "Marital satisfaction," Encyclopedia of Family Studies. John Wiley \& Sons, Inc., pp. 1-2, Mar. 2016, doi: 10.1002/9781119085621.wbefs054.

[17] Z. Tavakol, A. Nikbakht Nasrabadi, Z. Behboodi Moghadam, H. Salehiniya, and E. Rezaei, "A review of the factors associated with marital satisfaction," Galen Medical Journal, vol. 6, no. 3, pp. 197-207, 2017, doi: 10.22086/gmj.v6i3.641.

[18] A. Bilal and S. Rasool, "Marital satisfaction and satisfaction with life: Mediating role of sexual satisfaction in married women," Journal of Psychosexual Health, vol. 2, no. 1, pp. 77-86, Jan. 2020, doi: 10.1177/2631831820912873.

[19] A. K. Misura and H. Memisevic, "Quality of life of parents of children with intellectual disabilities in Croatia," Journal of Educational and Social Research, vol. 7, no. 2, pp. 43-48, May 2017, doi: 10.5901/jesr.2017.v7n2p43.

[20] J. Schmidt, M. Schmidt, and I. Brown, "Quality of life among families of children with intellectual disabilities: A slovene study," Journal of Policy and Practice in Intellectual Disabilities, vol. 14, no. 1, pp. 87-102, Dec. 2017, doi: 10.1111/jppi.12188.

[21] Y. W. Ki and C. C. Y. Joanne, "Stress and marital satisfaction of parents with children with disabilities in Hong Kong," Psychology, vol. 05, no. 05, pp. 349-357, 2014, doi: 10.4236/psych.2014.55045.

[22] S. L. Hartley, E. T. Barker, J. K. Baker, M. M. Seltzer, and J. S. Greenberg, "Marital satisfaction and life circumstances of grown children with autism across 7 years," Journal of Family Psychology, vol. 26, no. 5, pp. 688-697, 2012, doi: 10.1037/a0029354.

[23] S. L. Hartley, M. M. Seltzer, E. T. Barker, and J. S. Greenberg, "Marital Quality and families of children with developmental disabilities," in International Review of Research in Developmental Disabilities, vol. 41, no. C, 2011, pp. 1-29.

[24] J. W. Peer and S. B. Hillman, "Stress and resilience for parents of children with intellectual and developmental disabilities: A review of key factors and recommendations for practitioners," Journal of Policy and Practice in Intellectual Disabilities, vol. 11, no. 2, pp. 92-98, Jun. 2014, doi: 10.1111/jppi.12072.

[25] Y. Yamaoka, N. Tamiya, N. Izumida, A. Kawamura, H. Takahashi, and H. Noguchi, "The relationship between raising a child with a disability and the mental health of mothers compared to raising a child without disability in japan," SSM - Population Health, vol. 2, pp. 542-548, Dec. 2016, doi: 10.1016/j.ssmph.2016.08.001.

[26] M. W. Azeem et al., "Anxiety and depression among parents of children with intellectual disability in Pakistan," Journal of the Canadian Academy of Child and Adolescent Psychiatry, vol. 22, no. 4, pp. 290-295, 2013.

[27] J. Kersh, T. T. Hedvat, P. Hauser-Cram, and M. E. Warfield, "The contribution of marital quality to the well-being of parents of children with developmental disabilities," Journal of Intellectual Disability Research, vol. 50, no. 12, pp. 883-893, Dec. 2006, doi: $10.1111 / \mathrm{j} .1365-2788.2006 .00906 . x$.

[28] A. Siman-Tov and S. Kaniel, "Stress and personal resource as predictors of the adjustment of parents to autistic children: A multivariate model," Journal of Autism and Developmental Disorders, vol. 41, no. 7, pp. 879-890, Sep. 2011, doi: 10.1007/s10803-010-1112-x.

[29] M. Robinson and C. L. Neece, "Marital satisfaction, parental stress, and child behavior problems among parents of young children with developmental delays," Journal of Mental Health Research in Intellectual Disabilities, vol. 8, no. 1, pp. 23-46, Dec. 2015, doi: 10.1080/19315864.2014.994247.

[30] M. H. Sheikh, S. Ashraf, N. Imran, S. Hussain, and M. W. Azeem, "Psychiatric morbidity, perceived stress and ways of coping among parents of children with intellectual disability in Lahore, Pakistan," Cureus, Feb. 2018, doi: 10.7759/cureus.2200.

[31] D. B. Mitchell, A. Szczerepa, and P. Hauser-Cram, "Spilling over: Partner parenting stress as a predictor of family cohesion in parents of adolescents with developmental disabilities," Research in Developmental Disabilities, vol. 49-50, no. 2016, pp. 258267, Feb. 2016, doi: 10.1016/j.ridd.2015.12.007

[32] A. Chowdhury, "Families in Bangladesh," Journal of Comparative Family Studies, vol. 26, no. 1, pp. 27-41, Mar. 1995, doi: 10.3138/jcfs.26.1.27

[33] S. Akhtar, M. Estiak, K. Chowdhury, M. A. Islam, and M. Golam Mostofa, "Domestic violence against women and its determinants in some selected areas of Bangladesh," International Journal of Innovative Research in Engineering \& Management (IJIREM), vol. 5, no. 5, pp. 557-2350, 2018.

[34] A. Habib, F. Hossain, T. Ferdous, and K. M. Bayezid, "Social networks and social ties: changing trends among urban dwellers in

Int J Public Health Sci, Vol. 11, No. 1, March 2022: 211-219 
Bangladesh," OALib, vol. 05, no. 05, pp. 1-12, 2018, doi: 10.4236/oalib.1104604.

[35] A. T. Beck, R. A. Steer, and G. K. Brown, "Manual for the beck depression inventory the psychological corporation," San Antonio, TX, vol. 1, p. 1996, 1996.

[36] S. M. A. H. Mostafa Alim, M. N. Ahmed, M. S. I. Mullick, N. F. Chowdhury, F. Akhter, and M. S. Alam, "Validation of the Bangla version of beck depression inventory-II," Brain and Behavior, vol. 10, no. 3, pp. 1-11, Mar. 2020, doi: $10.1002 / b r b 3.1563$.

[37] S. S. Hendrick, A. Dicke, and C. Hendrick, "The relationship assessment scale," Journal of Social and Personal Relationships, vol. 15, no. 1, pp. 137-142, Feb. 1998, doi: 10.1177/0265407598151009.

[38] S. S. Hendrick, "A generic measure of relationship satisfaction," Journal of Marriage and the Family, vol. 50, no. 1, pp. 93-98, Feb. 1988, doi: 10.2307/352430.

[39] E. Y. Park and J. H. Kim, "Depression and life satisfaction among parents caring for individuals with developmental disabilities in South Korea," Journal of Developmental and Physical Disabilities, vol. 31, no. 4, pp. 453-469, Jan. 2019, doi: 10.1007/s10882-018-9647-4.

[40] N. Sapkota, A. K. Pandey, B. K. Deo, and M. K. Shrivastava, "Anxiety, depression and quality of life in mothers of intellectually disabled children," Journal of Psychiatrists' Association of Nepal, vol. 6, no. 2, pp. 28-35, Nov. 2018, doi: 10.3126/jpan.v6i2.21757.

[41] S. Gavidia-Payne and Z. Stoneman, "Erratum: marital adjustment of parents of young children with disabilities: Associations with daily hassles and problem-focused coping (American Journal on Mental Retardation (January 2006))," American Journal on Mental Retardation, vol. 111, no. 3, p. 198, 2006, doi: 10.1352/0895-8017(2006)111[198:E]2.0.CO;2.

[42] S. L. Hartley, E. T. Barker, M. M. Seltzer, J. S. Greenberg, and F. J. Floyd, "Marital satisfaction and parenting experiences of mothers and fathers of adolescents and adults with autism," American Journal on Intellectual and Developmental Disabilities, vol. 116, no. 1, pp. 81-95, Jan. 2011, doi: 10.1352/1944-7558-116.1.81

[43] C. Y. S. Leung and C. W. P. Li-Tsang, "Quality of life of parents who have children with disabilities," Hong Kong Journal of Occupational Therapy, vol. 13, no. 1, pp. 19-24, 2003, doi: 10.1016/s1569-1861(09)70019-1.

[44] S. Akhtar, R. Ahmed, A. S. Chaity, and M. Billah, "Association between knowledge and depression at rising time of COVID-19 in Bangladesh," International Journal of Public Health Science, vol. 10, no. 2, pp. 387-393, Jun. 2021, doi: 10.11591/ijphs.v10i2.20642.

\section{BIOGRAPHIES OF AUTHORS}

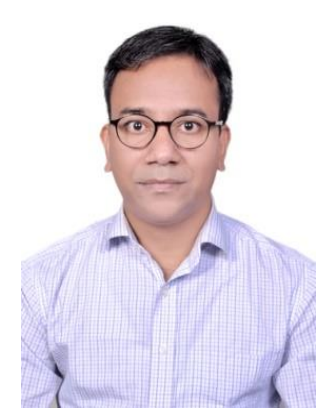

Mohammad Aminul Islam (iD SC $\mathrm{P}$ is a lecturer at the Department of Media Studies and Journalism, University of Liberal Arts Bangladesh (ULAB), Dhaka, Bangladesh. He received a master's degree in Mass Communication and Journalism from the University of Rajshahi, Bangladesh, and a bachelor's degree in Mass Communication from the same university. He also received a Post Graduate Diploma in Journalism (New Media) from the Asian College of Journalism, Chennai, India. Aminul's research interests include communication in healthcare, healthcare seeking behavior, media and psychiatry, media psychology, and cyberpsychology. He can be contacted at email: aminul.islam@ulab.edu.bd/aminul.vu@gmail.com.

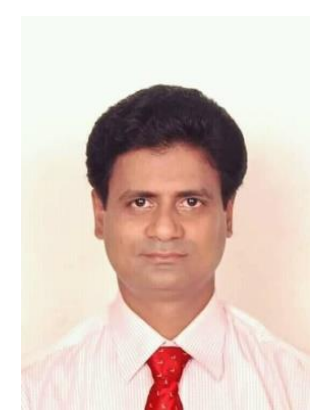

Md. Azibar Rahman (iD I8 SC P is an assistant professor at the Department of Psychology at Shalua Degree College, Charghat, Rajshahi. He did Ph.D. in psychology at the Department of Psychology at the University of Rajshahi. He also earned a master's degree and a bachelor degree from the same department of the university. His area of academic interest includes stress and coping attitudes of cancer and cardiac patients. He can be contacted at email: azrahman1975@gmail.com.

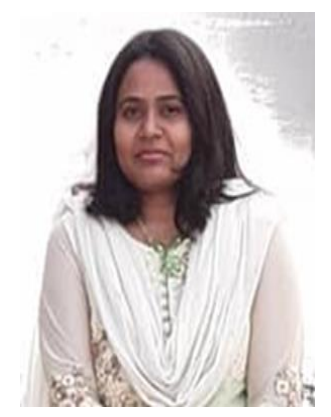

Sharmin Akhtar (D) SI SC P is a doctoral student at the department of psychology and social counselling at the University Malaysia Terengganu, Terengganu, Malaysia. She received a master of science and bachelor of science from the department of Population Science \& Human Resource Development, University of Rajshahi, Rajshahi, Bangladesh. She is also working as a program officer on the Ending Child Marriage through Adolescents Voice and Stakeholders Responsiveness project at Association for Community Development, Rajshahi, Bangladesh. She has published peer-reviewed scientific articles in some journals. I am interested in exploring psychosocial determinants of health and quality of life in the future. She can be contacted at email: sharmin.pop.sc.ru@gmail.com. 